\title{
Children Learning by Observing and Pitching In: Commentary
}

\author{
Elinor Ochs
}

University of California, Los Angeles, Calif., USA

\begin{abstract}
Key Words
Comparative studies - Constellations - Learning by Observing and Pitching In . Social control
\end{abstract}

\section{On Comparative Studies}

Just as history contextualizes a current state of affairs through accounts of past events, so comparative studies speak volumes about what is cultural in the way we live our lives from infancy to old age. Yet, while historical studies abound, few contemporary scholars dare to tread into the territory of comparative research, wincing at the critique that such an enterprise essentializes societies and ignores porous social boundaries, global flows, instabilities, transformations, and internal variability within and across persons and situations. Indeed, since the late twentieth century, anthropologists have decried "culture" as a blanket attribute of a population [Abu-Lughod, 1991].

But does hybridity and fragmentation mean that we cannot or should not overcome methodological shortcomings to sort out the shared and distinctive, resilient and shifting sentiments, beliefs, and practices associated with belonging to one or more communities? The study of "Learning by Observing and Pitching In" takes this step, offering a nuanced comparative perspective that taps into social changes in learning ecologies brought about by modernity and urban migration of indigenous populations in Latin America. The shift from subsistence agriculture to urban employment has reorganized not only household economies but also household ecologies of educating children.

In this perspective, cross-cultural comparison is not absolute but rather comprehends a continuum of default dispositions and practices undergirding the social organization of learning. "Learning by Observing and Pitching In" entails degrees of (1) routine incorporation of children's contributions in community endeavors, (2) a goal of transforming children's participation in community activities, imbued with

\begin{tabular}{l}
\hline KARGER \\
$\begin{array}{l}\text { E-Mail karger@karger.com } \\
\text { www.karger.com/hde }\end{array}$
\end{tabular}

Elinor Ochs

UCLA Department of Anthropology

341 Haines Hall - Box 951553

Los Angeles, CA 90095-1553 (USA)

E-Mail eochs@anthro.ucla.edu 
respect and responsibility, (3) children's eagerness to contribute and belong, (4) children's keen attention, (5) children's taking initiative and being part of an ensemble that does not require adult directives, (6) reliance on sparing communication embedded in ongoing shared endeavors, and (7) ongoing assessment of learner support and progress [Rogoff, this issue].

\section{On Constellations}

The "Learning by Observing and Pitching In" model provides a politically astute version of community of practice wherein community is not circumscribed and practice is specified as an element within a "constellation." The model is front and center in presenting the culturally porous and historically shifting character of communities in Guadalajara, Mexico, including "a town considered indigenous a generation ago" but currently engulfed by a nearby metropolis, "an urban community with extensive Western schooling in the last generation," and an urban community with Western schooling across several generations. Cultural hybridity is central to these descriptors, obviating the possibility of categorical comparisons between, for example, "us" and "them." Instead, we are introduced to a sliding scale of adherence to indigenous and European-origin practices across these communities. The mix is both synthetic and syncretic in that community members reconcile modern and folk beliefs.

The model's emphasis on a "constellation of practices" differs radically from a "repertoire of practices." As commonly understood, a constellation is a set of objects that form a picture or pattern, as in celestial constellations of stars. Alternatively, a repertoire is a set of works or skills that a person or social group is able to perform and/or routinely performs. The repertoire as a whole is not configured into a recognizable image. Walter Benjamin [2002] applied the term constellation to a grouping of juxtaposed objects, events and other elements that make recognizable an idea. In this sense, the constellation of practices discussed in this issue make recognizable the idea of "Learning by Observing and Pitching In."

Also compatible with Benjamin's [2002] account, the separable practices in the "Learning by Observing and Pitching In" constellation are imbued with temporality, pulled towards historical consciousness of the past and towards a projected future. The temporality of the constellation undergirds the comparative project, since the communities are linked through a cultural-historical habitus which varies in its present immanence and future prospects that beckon them towards greater cultural hybridity. Fueled by moral sentiments on the one hand and postcolonial economic pressures on the other, past and future pulls create a tension among the elemental practices. Benjamin might couch what is transpiring in metropolitan areas of Guadalajara as much more than a mere distancing of traditional practices. Rather, it is modernity's "tremendous shattering of tradition" [Benjamin, 1935, p. 223; as cited in Osborne, 2005, p. 320].

The fit between the "Learning by Observing and Pitching In" model and a constellation may be awkward when considering the definitional property that elements of a constellation are not bound by a unifying principle. Beyond their position in space, stars in a celestial constellation have no astronomical relation to one another. In contrast, the practices that form the "Learning by Observing and Pitching In" constellation are sometimes depicted as "integrated" in a "pattern of cultural practices" 
that undergirds cultural "coherence": "Viewing culture in terms of practices in which people engage aids us in developing an idea of the patterns of cultural practices that form whole constellations which may be more common in some communities than others, while recognizing change and variability within as well as across communities ... Cultural practices form somewhat integrated constellations in which specific practices relate to each other and cannot be isolated without destroying the coherence of culture" [Rogoff, Najafi, \& Mejía-Arauz, this issue]. Reference to "patterns of cultural practices" brings to mind Ruth Benedict's [1934] outmoded "patterns of culture," which assigned an emotional theme to each culture, assuming the theme to be unconsciously shared by all members. Benedict portrayed culture as an internally coherent configuration of traits perpetuated across generations through enculturation.

Reading through this issue's nuanced studies of attitudes and practices surrounding children's work in households, I am convinced that the authors in fact do not subscribe to Benedict's view of culture as patterned and coherent. Indeed, the same sentence that advocates "patterns of cultural practices" goes on to note "change and variability within as well as across communities." And the studies that follow detail precisely where and how such variability appears. Benedict saw variation in patterns of culture as deviations, but the approach taken in this issue views variation as normal, taking a bricolage approach to how Guadalajarans cobble together montages of practices.

A leitmotif of the "Learning by Observing and Pitching In" manifesto is that practices within this constellation are vulnerable to movement and shift. One practice (e.g., children's keen attention) or another (e.g., children's disposition to take initiative) may lose resilience. The fragility of particular practices within the constellation evidences conflict that, in turn, generates societal transformation. While more vibrant (though undergoing changes) in rural indigenous communities in the Americas, the "Learning by Observing and Pitching In" constellation is undergoing rapid transformation in urban areas. In these environments, "Learning by Observing and Pitching In" resembles the underwriting of a palimpsest. A palimpsest is a multilayered document in which earlier writing has been partially effaced but is still visible. As such, the palimpsest brings together multiple authors, symbols, and time frames to create a complex, historically contingent product. In this issue, the authors fruitfully decipher the traces of the constellation that have not been erased, even when overwritten by new influences. Like a palimpsest, these layers of practices comingle and change lived experiences of social order.

\section{On Scope}

Over the last three decades, there has been a groundswell of anthropological and psychological research on the social organization of attention and its significance for children's development. Corporeal alignments, gaze, gestures (especially pointing), touch, and speech are universally deployed to establish shared attention and orient infants and young children to their surroundings. Some approaches begin with the caregiver-infant dyad cooperating around a common goal as the origo of culture and language [Clark, 2001; Tomasello, Carpenter, Call, Behne, \& Moll, 2005]. Others begin with the habitus of the community as the anchor point of actively engaged infants 
[Cole, 1996; Rogoff, 1990]. And still others strive to understand how communities and infants are participants in and agents of social, economic, and moral continuity and change [de León, 1998; Garrett, 2005; Heath, 2012; Ochs \& Schieffelin, 2012; Paugh, 2012; Rogoff, 2003].

The "Learning by Observing and Pitching In" model dovetails with all three endeavors, but its heart and soul are aligned with the last, more radical enterprise wherein communities and children are coengaged with one another's transformation. While Vygotsky's genetic method long ago insisted on the integration of ontogenesis and social history [Wertsch, 1985], few have exercised the cultural and developmental expertise and intellectual stamina to carry out a double-barreled analysis. The "Learning by Observing and Pitching In" model of childhood and community builds upon a rare combination of long-term ethnographic field observations and socioculturally situated experiments conducted across rural and urbanized indigenous and nonindigenous populations and settings. The model emerges from a steady stream of cultural apprenticeship theories generated in Rogoff s laboratory at the University of California, Santa Cruz, and elsewhere.

In many ways, the "Learning by Observing and Pitching In" model represents a convergence of perspectives of cultural psychology and language socialization on the sociocultural organization of childhoods. In 1978, I landed in what was then called "Western Samoa" (now Samoa) to conduct a language acquisition study in the village of Falefa. As soon as I began recording children, two related features of young children's lives impressed me: (1) Little ones were constantly surrounded by many kin and neighbors, facilitated by open-sided houses built along roads where everyone passed by, and (2) adult and sibling caregivers held toddlers outward to these folks, prompting them to call out to them, orchestrating attention to people and what they were doing as a foundation of respect and knowledge [Ochs, 1988]. These field observations mirrored Bambi Schieffelin's observations of Kaluli children growing up in densely inhabited Papua New Guinean longhouses [Schieffelin, 1990]. We proposed that societies divide along two prevailing socialization practices: In some societies (e.g., Samoan, Kaluli) adults spend considerable effort orienting little children to accommodate to the needs of the situation; in other societies (e.g., Euro-American middle class) adults exert considerable effort accommodating the situation to the perceived needs of young children [Ochs \& Schieffelin, 1984].

The first orientation (child accommodates to situation) overlaps with "Learning by Observing and Pitching In" in terms of three shared features: (1) routine incorporation of children's contribution in community endeavors, (2) children's keen attention, and (3) ongoing assessment of children's contribution to community activities. As in indigenous communities in Latin and South America, Samoan and Kaluli children were proximal to domestic, economic, and religious activities. Given that multiparty interactions were the norm, infants and young children had limitless opportunity not only to be observers of activities and overhearers of conversations but also to be participants as they displayed competence. Samoan caregivers generally did not simplify talk to infants, but children nonetheless quickly acquired common and respect language and delivered messages appropriately to untitled and titled persons by the age of 4 years.

Important to the matter of cross-cultural scope, three features of the "Learning by Observing and Pitching In" model do not characterize the Samoan and Kaluli practices documented in field recordings. The restricted features include: (1) chil- 
dren's eagerness to contribute and belong, (2) children's taking initiative and being part of an ensemble that does not require adult directives, and (3) reliance on sparing communication embedded in ongoing shared endeavors. These features are loosely linked in that eager children who take initiative may indeed not require adult directives or other forms of language to motivate involvement and learning. Instead, language played a more central role in recruiting and modulating Samoan and Kaluli children's work contributions. This difference suggests that the "Learning by Observing and Pitching In" model is variably configured not just along rural-to-urban lines but also across rural communities with mixed economies in different areas of the world.

Young Samoan and Kaluli children perform many chores beginning at a very young age. As in the "Learning by Observing and Pitching In" model, knowledge is acquired through repeated observation and experimentation. Yet children were not usually eager to contribute their labor, and they characteristically did not take initiative in performing domestic, subsistence, civic, and church-related tasks. Instead, they often did so in response to a barrage of directives and prompts issued by older children or adults. Once roused, young children performed the chores, but they also whined and were admonished. Kaluli girls were asked to perform so many more tasks than were boys that 6-year-old girls did not want to wear gender-marked skirts. It was not uncommon for Samoan and Kaluli children to shunt a work assignment to another child lower in the pecking order. In rare but hotly discussed incidents, a Samoan child would become "musu," an extended shutdown state of complete refusal. Children's efforts were monitored by the vigilant eyes of kin and neighbors close at hand. Rather than "sparing communication," those surrounding children vocally calibrated and corrected their actions ("Cover the baby's head!" or "Don't!"). Teasing, shaming, and threats were ubiquitous. These provocations were never used to stigmatize or marginalize a child, but rather to draw attention to and discourage certain actions [Schieffelin, 1986]. Verbal confrontation as correction is widespread as a socialization strategy [cf. Briggs, 1971; Brown, 2002; Miller, 1986; Paugh, 2012].

The "Learning by Observing and Pitching In" model hypothesizes that the sociocultural orchestration of children's contributions to household and community activities is vital far beyond the activities themselves. Children learn executive-function skills, autonomy, self-esteem, cooperation, citizenship, empathy, ethics, and other forms of intelligence. I could not agree more.

In addition, it is important to emphasize that when families and communities direct children's "keen attention" to people, they learn how to mobilize and sustain particular relationships beyond membership in the family and community. Kaluli children, for example, learn how to forge the all-important and affect-loaded older sister-younger brother (ade) relationship. Samoan children learn how to use a special respect register for talking to persons of higher social status. Whereas egalitarian Mesoamerican communities emphasize reciprocal displays of mutual respect, Samoan communities are deeply hierarchical, with social encounters in and outside the home entailing a calculation of relative age, generation, and title. For Samoans, the concept of attention is morphologically integrated into the Samoan term for respect, "fa'aaloalo," which literally means "cause-to-turn-towards-face." Across all communities, paying attention and contributing to valued endeavors is the glue of core social relationships. And, moreover, learning how to forge and sustain these distinct relationships is the prerequisite for reaping continued benefits of one another's efforts. 


\section{On Social Control}

This commentary concludes with a consideration of where control is lodged in societies and its import for the sociocultural integration of children. Social control operates on at least two basic levels: (1) institutionally sanctioned control strategies, and (2) psychological accommodation to normative social order.

On one level, social control boils down to specific strategies deployed by institutions, including families, for getting members of society to conform to what is expected and desired. The "Learning by Observing and Pitching In" model primarily addresses such strategies of social regulation by way of highlighting a constellation of practices variably deployed across communities characterized by degrees of identification with indigenous heritage. As a capstone of this analysis, Coppens, Silva, Ruvalcaba, Alcalá, López, and Rogoff [this issue] propose a "third way" of involving children in household and community endeavors beyond the cross-cultural alternatives of caregivers soliciting help or delegating responsibility for tasks [Ochs \& Izquierdo, 2009]. The third way consists of adults and children engaging collaboratively in endeavors, which "removes adults from a controlling, assigning role and instead makes room for both adults and children to take initiative in pitching in, with autonomy as well as responsibility." The third way aligns with the concepts of "collective agency" and "collective initiative" championed as collateral of the "Learning by Observing and Pitching In" constellation. The third way is a welcome addition to the range of possibilities for maximizing children's task involvement.

As noted, cross-cultural distinctions are variable rather than categorical. Thus, all societies rely upon a range of social control strategies including soliciting help, delegation of responsibility, and collective initiative to pitch in and collaborate in an activity. The differences manifest in variation in a behavior or disposition's moral weight, prevalence, situational context, and the like. Samoan kids, for example, were often roused by a directive (strategy 1 ) to perform a task for which they have been generally delegated to be responsible (strategy 2) and whose accomplishment is viewed as a cooperative rather than individual effort (strategy 3 ). The collected papers here suggest that indigenous communities in Mexico display a version of all three strategies but a strong preference for collective initiative (strategy 3 ) and a dispreference for adult assignment of individual responsibility for a task (strategy 2).

In the domain of social regulation strategies, the locus of control is lodged somewhere in the social situation - in the issuer of a directive, the delegator of responsibility, or the collective initiators of cooperative endeavors. When social theorists gauge social control, however, the locus is embedded in social order itself and its resonance in the consciousness of individuals. Foucault [1979], for example, sees panoptical control in the architecture of buildings. From this point of view, social control in rural Samoan communities is lodged in the panopticon-oriented open dwellings and family compounds.

In addition, the lived experience of social control is essential, especially individuals' understandings of and affiliation with values and expectations of others. Social regulation thus extends beyond acts, rules, laws, and institutions that enforce what is considered normative. Instead, it entails an abiding moral willingness of each person to adhere to prevailing social norms. This willingness is captured in Foucault's "normalizing judgment" [Foucault, 1979] and Gramsci's [1971] "cultural hegemony." For both scholars, children's informal and formal education induces a psychological ac- 
commodation to the status quo as normal, natural, and grounded in common sense. The patient collective initiatives of Indigenous American communities with children and the hierarchical orders issued to children in Samoan communities equally exact high degrees of accommodation to social control; apparently different modes of apprenticeship and communication, they continuously and collaboratively renew culture in the consciousness of the next generation.

This consciousness is displayed early in life: At the single-word stage, for example, Samoan children know that it is appropriate to use the affect-marked pronoun "poor me" or the verb "give" to beg for food from elders, but that it is disrespectful to ask them to "come" to them. Similarly, 2-year-old Mexican Nahua children begin to meet social expectations to perform housework. By the time indigenous Mexican children are 6-8 years old, many are able to perform difficult domestic work that requires considerable prowess, like cooking and ironing. The social control implication is that as children learn to perform expected behaviors and skills, they normalize their conduct and the more pervasive forms of social control that undergird it, including the deep culture of learning itself [Bateson, 1972].

Throughout the world, the sense of what is natural and normal about a way of life has been vulnerable to contact zones between colonial powers and indigenous populations, migration, industrialization, popular culture, and other influences [Pratt, 1991]. Unequal differences in power and wealth have ushered in widely varying ideologies that render indigenous practices and competencies subject to fragmentation, doubt and conflict. This issue makes an important contribution to understanding these effects of power and modernity. With respect to the indigenous constellation of "learning by observation and pitching in," the authors document how, dependent upon informal social regulation within households and communities, its core practices and ideology have become diluted in urban households with indigenous backgrounds. In these families, children tend to display less initiative in chores, homework, and organizing their free time. Although formal schooling may be influential in this trend, the greater emphasis on individual self-interest is enmeshed in the massive private-sector industrial economy of Guadalajara and other cities in Latin America. In addition, as noted in this issue, concomitant with joining the urban labor force, metropolitan families may have fewer children, which may afford child-centric aspirations.

Yet what this issue makes equally compelling is the persistence of certain traditional voices in the plurality of social influences. The issue demonstrates precisely how indigenous metropolitan families, long in the throes of modernity, maintain remnants of their historical lifeworld, the world that they have experienced with certain others [Husserl, 1970]. Caught between increasingly distant remembered yearnings and vividly present emergent forms of social regulation and ideologies [Williams, 1977], these households are generating their own heterogeneous constellations of practices, conflicts and all.

\section{On the Ethnographic Subjunctive}

Anthropologists are generally trained to assume a culture-relative stance and suspend moral judgment in their field sites. Increasingly, however, anthropologists have been proactive in documenting practices that diminish the vitality of a person 
or a group. Threaded throughout this issue is advocacy of the "Learning by Observing and Pitching In" constellation of practices and nostalgia for its waning presence in cosmopolitan family life. In line with language and culture revitalization projects elsewhere, they have taken first steps to halt the demise of this constellation, training a few teacher-research assistants in indigenous practices that enhance children's initiative, attention, and collaborative involvement at a calm pace [Paradise, MejíaArauz, Silva, Roberts, \& Rogoff, this issue]. This has not been an easy exercise. Looming large is the challenge of transforming schools into semblances of multiparty activity settings where children can observe and participate. Plus, the inertia of the teacher-centric habitus of instruction provokes teachers' anxieties and resistance. The reader feels the authors' imperative that there is much for teachers and all of us to gain from indigenous ways of learning, but the road is steep.

Ultimately, this treatise on "Learning by Observing and Pitching In" exceeds the specifications of a report of findings. In a mixture of hope and trepidation, the authors provide an ethnographic subjunctive that projects a realm of possibilities of what could be for families, schools, and communities.

\section{References}

Abu-Lughod, L. (1991). Writing against culture. In R.G. Fox (Ed.), Recapturing anthropology (pp. 137162). Santa Fe: School of American Research Press.

Bateson, G. (1972). Steps to an ecology of mind. New York: Ballantine Books.

Benedict, R. (1934). Patterns of culture. Boston: Houghton Mifflin.

Benjamin, W. (1968/1935). The work of art in the age of mechanical reproduction. In Illuminations. New York: Schocken Books.

Benjamin, W. (2002). Critical constellations. Oxford: Polity Press.

Briggs, J. (1971). Never in anger: Portrait of an Eskimo family. Cambridge: Harvard University Press.

Brown, P. (2002). Everyone has to lie in Tzeltal. In S. Blum-Kulka \& C. Snow (Eds.), Talking to adults (pp. 241-275). Mahwah: Erlbaum.

Clark, E.V. (2001). Grounding and attention in language acquisition. Papers of the Chicago Linguistic Society, pp. 95-116.

Cole, M. (1996). Cultural psychology: A once and future discipline. Cambridge: Harvard University Press.

de León, L. (1998). The emergent participant: Interactive patterns of socialization of Tzotzil (Mayan) children. Journal of Linguistic Anthropology, 8, 131-161.

Foucault, M. (1979). Discipline and punish: The birth of the prison. New York: Random House.

Garrett, P. (2005). What a language is good for: Language socialization, language shift, and the persistence of code-specific genres in St. Lucia. Language in Society, 34, 327-361.

Gramsci, A. (1971). Selections from the prison notebooks of Antonio Gramsci. Translated by Q. Hoare \& G.N. Smith. New York: International.

Heath, S.B. (2012). Words at word and play: Three decades in family and community life. Cambridge: Cambridge University Press.

Husserl, E. (1970). The crisis of European sciences and transcendental phenomenology. Evanston: Northwestern University Press.

Miller, P. (1986). Teasing as language socialization and verbal play in a white working-class community. In B. Schieffelin \& E. Ochs (Eds.), Language socialization across cultures (pp. 199-212). Cambridge: Cambridge University Press.

Ochs, E. (1988). Culture and language development: Language acquisition and language socialization in a Samoan village. Cambridge: Cambridge University Press.

Ochs, E., \& Izquierdo, C. (2009). Responsibility in childhood: Three developmental trajectories. Ethos, 37, 391-413.

Ochs, E., \& Schieffelin, B.B. (1984). Language acquisition and socialization: Three developmental stories. In R.A. Shweder \& R.A. LeVine (Eds.), Culture theory: Essays on mind, self, and emotion (pp. 276320). Cambridge: Cambridge University Press.

Ochs, E., \& Schieffelin, B.B. (2012). The theory of language socialization. In A. Duranti, E. Ochs, \& B.B. Schieffelin (Eds.), The handbook of language socialization (pp. 1-22). Malden: Wiley-Blackwell.

Commentary on Learning by Observing and Pitching In
Human Development 2014;57:162-170 169 DOI: $10.1159 / 000359915$ 
Osborne, P. (Ed.) (2005). Walter Benjamin: Critical evaluations in cultural theory. Vol. 1: Philosophy. London \& New York: Routledge.

Paugh, A. (2012). Playing with language: Children and change in a Caribbean village. New York: Berghahn Books.

Pratt, M.L. (1991). Arts of the contact zone. New York: Modern Language Association.

Rogoff, B. (1990). Apprenticeship in thinking. New York: Oxford University Press.

Rogoff, B. (2003). The cultural nature of human development. Oxford: Oxford University Press.

- Schieffelin, B.B. (1986). Teasing and shaming in Kaluli children's interactions. In B.B. Schieffelin \& E. Ochs (Eds.), Language socialization across cultures (pp. 165-181). Cambridge: Cambridge University Press.

-Schieffelin, B.B. (1990). The give and take of everyday life: Language socialization of Kaluli children. Cambridge: Cambridge University Press.

Tomasello, M., Carpenter, M., Call, J., Behne, T., \& Moll, H. (2005). Understanding and sharing intentions: The origins of cultural cognition. Behavioral and Brain Sciences, 28, 675-690.

Wertsch, J. (1985). Vygotsky and the social formation of mind. Cambridge: Harvard University Press.

Williams, R. (1977). Marxism and literature. Oxford: Oxford University Press. 